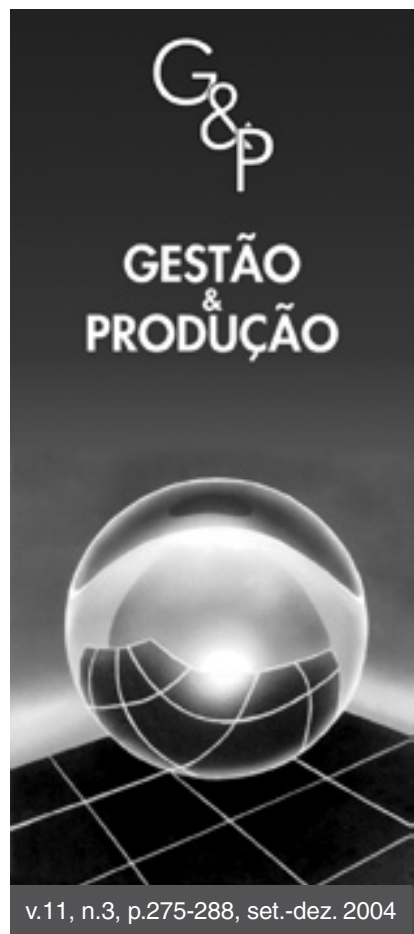

\title{
PRESSUPOSTOS DA GESTÃO DA CADEIA DE SUPRIMENTOS: EVIDÊNCIAS DE ESTUDOS SOBRE A INDÚSTRIA AUTOMOBILÍSTICA
}

\author{
Alceu Gomes Alves Filho \\ Aline Lamon Cerra \\ Jonas Lucio Maia \\ Mario Sacomano Neto \\ Patricia Viera Grizola Bonadio
}

Departamento de Engenharia de Produção, Universidade Federal de São Carlos, C.P. 676, CEP 13565-905, São Carlos, SP

e-mail: alceu@power.ufscar.br

Resumo

Recebido em 30/6/2004

Aceito em 23/11/2004

O desenvolvimento de abordagens para estudo de cadeias de suprimentos é relativamente recente e vem sendo tratado em periódicos científicos, de modo sistemático, apenas a partir do final dos anos 80. Neste artigo, são apresentados, inicialmente, os principais pressupostos da abordagem que ficou conhecida como Gestão da Cadeia de Suprimentos (GCS). Em seguida, procura-se ilustrar, a partir de uma revisão parcial de trabalhos realizados sobre a indústria automobilística, em que medida tais pressupostos podem, ou não, ser verificados. Constatando que apenas em alguns casos o conjunto de pressupostos tende a se tornar realidade, sugere-se que seja desenvolvida uma etapa metodológica inicial para a verificação de tais pressupostos ou para a avaliação das características estruturais e relacionais da cadeia de suprimentos a ser estudada. Procurando contribuir para o desenvolvimento dessa primeira etapa metodológica, faz-se uma breve síntese de algumas correntes teóricas que podem oferecer subsídios para a análise das características estruturais e relacionais principais da cadeia de suprimentos. Tal análise auxilia a avaliar o contexto em que princípios e técnicas da GCS poderão ser propostos e implementados e, também, pelo menos parcialmente, os resultados que poderão ser alcançados.

Palavras-chave: cadeias de suprimentos, pressupostos da gestão da cadeia de suprimentos, indústria automobilística.

\section{Introdução}

São relativamente recentes os esforços para desenvolvimento de abordagens para o estudo de cadeias de suprimentos. Apenas no final da década de 80, lastreado pelo amplo desenvolvimento da logística, o assunto começa a ser sistematicamente tratado em periódicos científicos nas áreas de Administração e Engenharia de Produção no ocidente, concomitantemente à difusão do novo padrão de relacionamento entre empresas, oriundo da indústria automobilística japonesa.

A partir de então, cresceram exponencialmente tanto a literatura mais prescritiva quanto aquela que analisa as situações e as práticas implementadas para a coordenação ou gestão de cadeias de suprimentos, tendo sido abordada uma variedade de temas cuja amplitude vai além dos limites definidos pelos fluxos de bens e pelos correspondentes fluxos de informações. É também evidente a difusão acelerada do conjunto de ferramentas e a multiplicação de aplicações, em diversos setores da economia, do que se convencionou denominar "Gestão da Cadeia de Suprimentos" (GCS), um corpo de conhecimentos ainda em construção que pode ser aplicado com a finalidade de coordenar as ações/atividades das diversas empresas ou unidades produtivas que constituem os elos e a cadeia de elos para a produção de um conjunto de bens e serviços.

Em função dessa variedade de temas e desse desenvolvimento recente e dada, ainda, a variedade de tipos 
das cadeias analisadas, de setores em que estão inseridas, de localização de seus elos, de extensão das parcelas das cadeias (subconjunto de elos) que são examinadas nos trabalhos e, principalmente, de objetos de análise escolhidos, a literatura contempla propostas metodológicas heterogêneas, ou ainda não consolidadas, mesmo quando estes objetos estão bem delimitados. Na raiz da heterogeneidade metodológica, situam-se os pressupostos principais sobre o objeto de estudo: as cadeias de suprimentos. Especialmente a literatura de cunho mais prescritivo, e mesmo a literatura empírica, assume um conjunto de pressupostos e não propõe uma etapa metodológica inicial que poderia contemplar a avaliação (verificação ou não) de tais pressupostos ou a identificação das características estruturais e relacionais principais das cadeias de suprimentos examinadas.

Em muitos casos, esses pressupostos não são explicitados ou, então, são enunciados como princípios norteadores de práticas de gestão mais eficazes, como se o conjunto destes pudesse ser adotado e ser o mais eficaz e eficiente em quaisquer circunstâncias. Admite-se que os pressupostos fornecem uma base sólida para um conjunto de princípios. Admite-se que, seja qual for a situação da cadeia de suprimentos, a implementação do modelo de produção enxuta ou de cadeia enxuta (lean supply) irá tornar a cadeia mais eficaz/eficiente e, portanto, pode-se passar, rapidamente, à avaliação de quão eficiente ou eficaz cada cadeia é, conforme são adotados os elementos que constituiriam a cadeia enxuta e a correspondente gestão da cadeia enxuta ou GCS.

Como uma avaliação do conjunto de pressupostos da GCS não foi até o momento sugerida pela literatura, embora tenha sido iniciada por alguns poucos autores (New, 1996, por exemplo), retoma-se aqui uma discussão sobre os pressupostos principais e freqüentemente mencionados. Essa discussão justifica a proposição de uma etapa metodológica inicial para os estudos sobre cadeias de suprimentos e sobre GCS. Partindo desse objetivo, este texto está organizado da seguinte forma. Inicialmente, são apresentados os principais pressupostos da GCS encontrados na literatura, e é proposto um determinado agrupamento, de acordo com características comuns que estes contemplem. Indicações de características de algumas cadeias de suprimentos do setor automobilístico e de autopeças, a partir de uma revisão da literatura, são apresentadas na seção seguinte e constituem evidências de que os pressupostos podem ser verificados em certos casos, mas não em outros. Apresentam-se, então, três correntes de pensamento que também focalizam cadeias de suprimentos e relações entre empresas: a Análise de Redes, a Dependência de Recursos e a Economia de Custos de Transação, procurando-se destacar como estas podem contribuir para a verificação e discussão dos pressupostos previamente apresentados. Na última seção, considerações finais são traçadas, propondo-se que as pesquisas sobre cadeias de suprimentos incluam uma etapa metodológica inicial de identificação e avaliação das características estruturais e relacionais das cadeias a serem analisadas ou, em outras palavras, de identificação e avaliação das configurações das cadeias de suprimentos.

\section{A gestão da cadeia de suprimentos e seus pressupostos}

O termo "Gestão da Cadeia de Suprimentos" (GCS) é relativamente novo, tendo sido proposto pela primeira vez na literatura na década de 80 (Cooper, Lambert e Pagh, 1997). Apesar disto, apenas nos anos 90 aparecem os primeiros relatos de empresas que envidaram esforços, já consoantes com essa abordagem, superando a visão tradicional, orientada excessivamente para os problemas internos, e focalizando a gestão de suas relações com as demais empresas que compõem as cadeias de suprimentos.

Segundo Pires (1998), essa nova abordagem (ou novo conjunto de práticas) tem trazido contribuições para empresas de diversos setores, sobretudo para a automobilística - que neste estudo é utilizada para constituir o conjunto das ilustrações. A indústria automobilística tem servido como setor paradigmático nas questões relacionadas à Administração da Produção e à Gestão da Cadeia de Suprimentos, especialmente com o advento da Produção Enxuta (ou Produção Flexível, ou Toyotismo).

Despertado o interesse nos campos empresarial e acadêmico ao longo da década de 90, observa-se, então, significativa expansão da literatura a respeito da abordagem de Gestão da Cadeia de Suprimentos e do conjunto de técnicas que apóiam sua implementação. Nesta literatura, pode-se verificar que o sistema de gestão (da Cadeia de Suprimentos) proposto implica uma série de pressupostos, mas raramente os próprios pressupostos são discutidos. Estes teriam de ser verificados ou assumidos pelas organizações na "prática", para que se pudesse afirmar que as práticas de gestão, derivadas destes pressupostos, seriam aplicáveis e produziriam os resultados esperados.

A seguir, encontram-se descritos os principais pressupostos de Gerenciamento da Cadeia de Suprimentos mencionados na literatura. Opta-se aqui por agrupá-los em quatro subconjuntos, relacionados, respectivamente, (1) ao ambiente competitivo, (2) ao alinhamento estratégico das organizações e à repartição de ganhos, (3) à estrutura da cadeia e (4) às relações entre as empresas na cadeia.

Grande parte da literatura sobre GCS propõe, de acordo com esses pressupostos, que uma GCS eficaz irá propiciar que atividades, processos, fluxos de materiais e informações estejam alinhados e integrados de modo a atender às necessidades de mercado, agregando valor aos produtos e serviços oferecidos. Segundo Cooper, Lam- 
bert e Pagh (1997), o Supply Chain Management (ou a GCS) é a integração dos processos de negócio desde o usuário final até os fornecedores originais, que proporcionam produtos, serviços e informações que agregam valor para o cliente. Desse modo, admite-se que as características das cadeias podem ser transformadas pela prática da GCS, com benefícios para as empresas que compõem a cadeia de suprimentos.

$\mathrm{O}$ primeiro subconjunto de pressupostos refere-se a como empresas e pesquisadores percebem o ambiente competitivo. Os demais subconjuntos referem-se a como empresas e pesquisadores percebem os comportamentos das empresas nas cadeias de suprimentos, incluindo elementos de suas estratégias, da divisão de trabalho entre os elos e do padrão de relacionamento existente entre estes.

\subsection{Ambiente competitivo}

O primeiro dos pressupostos, e o mais importante, embasa todos os outros aqui apresentados. De acordo com Christopher (1997), tem ocorrido uma reconfiguração do ambiente competitivo, de forma que a competição passou a ocorrer entre cadeias inteiras, e não mais entre empresas isoladamente. Deste modo, tem-se o seguinte pressuposto:

- A competição deve ocorrer entre cadeias e não mais entre empresas isoladas.

\subsection{Alinhamento estratégico e repartição de ganhos}

Um segundo grupo de pressupostos decorre imediatamente do primeiro. Se a competição agora ocorre entre cadeias de suprimentos, segue que as empresas devem ter suas estratégias alinhadas, de modo que as ações individuais produzam ganhos para toda a cadeia. A contrapartida do alinhamento estratégico seria, então, uma repartição dos ganhos equânime entre as empresas, conforme o esforço e o investimento de cada uma. Internamente à cadeia, haveria então um jogo de soma positiva e não um jogo de soma zero, em que uma empresa ganha apenas quando a outra perde. A teoria sobre GCS propõe, então, que as empresas integrantes da cadeia devem repartir os ganhos de modo equilibrado e equânime, sem assimetrias (Cooper, 1997 apud Trienekens, 1999):

- Os benefícios devem ser distribuídos a todos os integrantes da cadeia. Não deve haver, na cadeia, empresas "vencedoras" e empresas "perdedoras".

Baum e Dutton (1996) discutem o enredamento (embeddedness) das estratégias no contexto das relações entre firmas. Mencionam a possibilidade de alinhamento e o condicionamento das estratégias competitivas, pelo fato das empresas fazerem parte de cadeias de suprimentos. Deste modo, o próximo pressuposto pode ser enunciado como:
- As estratégias competitivas das empresas participantes da cadeia devem estar alinhadas.

\subsection{Estrutura da cadeia}

Na mesma linha de argumentação e ainda sustentado pelo primeiro pressuposto, um terceiro grupo pode ser divisado, focalizando aspectos importantes das estruturas das cadeias. Neste terceiro grupo, podem-se incluir aspectos relacionados a como os papéis das empresas ou unidades produtivas estão distribuídos nas cadeias, ou, em outras palavras, como o trabalho está dividido entre as empresas ou unidades produtivas, entre os elos da cadeia de suprimentos, e como atividades e processos são realizados.

A literatura propõe inicialmente que haja uma organização hierárquica, com papéis bem definidos, em que os fornecedores estão organizados em níveis, estabelecendo relações cooperativas - com fornecedores no mesmo nível e com fornecedores nos demais níveis -, e são coordenados (em parte pelo menos) pelos fornecedores nos níveis superiores (mais próximos dos clientes ou mais importantes, na definição dos negócios na cadeia).

Com a introdução das modernas práticas de gerenciamento, como o Just In Time e o TQM - Total Quality Management - , passou a ser fundamental o estabelecimento de relações mais estreitas com os fornecedores, para que os produtos pudessem ser entregues com qualidade assegurada e nas quantidades e prazos corretos. Para permitir tais relações, a perspectiva da GCS promove a redução do número de fornecedores (Lummus, Vokurka e Alber, 1998). Tal redução deve permitir e estimular uma cooperação que, segundo Mchug, Humphreys e Mclvor (2003), será tão mais intensa quanto maior for a participação do custo do produto fornecido no produto final. Deste modo o próximo pressuposto é:

- Os fornecedores devem estar organizados hierarquicamente, com um número relativamente pequeno de fornecedores em cada nível da cadeia.

Cooper, Lambert e Pagh (1997) e Trienekens (1999) afirmam que o Supply Chain Management lida com a integração dos processos de negócios através de toda a cadeia de suprimento, envolvendo a integração de funções e processos no interior de cada empresa e entre as empresas. Assim:

- As atividades e os processos, mesmo aqueles distribuídos por várias empresas, devem estar integrados na cadeia de suprimentos.

Internamente a cada firma, Wild (1995) comenta que a "integração funcional" visa diminuir ou remover as divisões entre funções pela união de atividades, sendo o mesmo conceito passível de ser aplicado nas relações inter-firmas. Desta forma, a Gestão da Cadeia de Supri- 
mentos visa maximizar a sinergia existente entre todas as partes da cadeia, de forma a atender o cliente final da maneira mais eficaz e eficiente possível. A idéia de integração no contexto intra e inter-empresarial é reforçada por Tan (2002), na medida em que o autor afirma que a filosofia subjacente à GCS focaliza a maneira pela qual as firmas implementam os seus processos de fornecimento, a tecnologia, a capacidade de aumentar a vantagem competitiva e a coordenação das funções de produção, logística e materiais, tanto dentro de cada firma como entre as firmas (intra-firma como inter-firmas).

Como decorrência da integração das várias áreas funcionais dentro e fora da empresa, tem-se o pressuposto de que as empresas devem estar todas dispostas a cooperar, para que haja um fluxo de produtos e de informações eficiente (Pires, 2004; Cooper, Lambert e Pagh, 1997). Para Lambert, Emmelhainz e Gardner (1996), deve haver um fluxo bidirecional de produtos (materiais e serviços) e de informação, entre todas as empresas constituintes da cadeia. Assim, o pressuposto é:

- Os fluxos de materiais, serviços e informações devem ser bidirecionais, ocorrendo entre todas as empresas pertencentes à cadeia.

Segundo Slack, Chambers e Johnston (2002), a eficiência operacional se relaciona aos esforços que cada operação na cadeia pode fazer, para reduzir sua própria complexidade. Deve-se ressaltar o efeito cumulativo destas atividades individuais, as quais simplificam as operações de toda a cadeia. Deste modo, tem-se:

- Cada empresa, em cada elo da cadeia, deve buscar eficiência operacional, tendo em vista a otimização das atividades da cadeia como um todo.

\subsection{Relações entre empresas}

Por fim, e como já indicado, para que haja alinhamento estratégico, integração de processos e funções é necessário haver relações cooperativas entre as empresas que constituem as cadeias de suprimentos.

Com as mudanças no ambiente competitivo global, verifica-se o crescimento do interesse pelos vários tipos de alianças ou parcerias estratégicas entre as empresas. Segundo Pires (1998); Bowersox e Closs (1996), as empresas devem abandonar a forma tradicional de relacionamento - em que havia a simples relação de compra e venda, sem qualquer caráter colaborativo - e passar a adotar relacionamentos mais estáveis e cooperativos com seus fornecedores.

Segundo Ballou (2001); Eulália apud Abdala (2002); Bowersox e Closs (1996); Mchug, Humphreys e Mclvor (2003) e Ellran apud Miranda (2002), a busca por relacionamentos mais estáveis tem ocorrido em função da impossibilidade de uma única empresa exercer controle sobre o fluxo produtivo, desde a fonte de matéria-prima até o ponto de consumo final. Desta forma, é necessário que tais relacionamentos de longo prazo sejam pautados pela cooperação e pela parceria, e não pela competição ou por relacionamentos conflituosos, para que todas as empresas pertencentes à cadeia possam alcançar vantagens competitivas. Para exemplificar um tipo de relacionamento cooperativo, pode-se citar a realização de investimentos conjuntos em P\&D e o envolvimento dos fornecedores nos processos de desenvolvimento e fabricação dos produtos. Deste modo, tem-se:

- As relações entre empresas devem ser cooperativas e de longo prazo.

A Figura 1 mostra o conjunto dos principais pressupostos associados à teoria de Gestão da Cadeia de Suprimentos. Como indicado, as características das cadeias referentes aos grupos de pressupostos condicionam-se mutuamente e, ainda, condicionam e são condicionadas pelas práticas da GCS. Quando as características da cadeia corresponderem ao estipulado nos pressupostos, as práticas da GCS serão mais facilmente implementadas, reforçando as características indicadas nos pressupostos. Quando não corresponderem, será provavelmente mais difícil e demorada a implementação da GCS. Em conjunto, como já mencionado, os pressupostos sustentam os princípios que orientam a GCS, e esta, por sua vez, propõe a utilização de diversas técnicas que visam promover o alinhamento, a integração e a gestão eficaz dos processos de negócios que atravessam as fronteiras das organizações constituintes de cada cadeia de suprimentos.

Esses pressupostos, os princípios e as práticas da GCS constituem o que se poderia denominar a "abordagem única de GCS". Dois conjuntos de questões são então cruciais: (1) A gestão individual em cada empresa e a gestão coletiva na cadeia são contingentes das características contempladas nos pressupostos mencionados e, eventualmente, de outras características aqui não consideradas? Seria necessário, então, abandonar a lógica da abordagem única para que alternativas de GCS pudessem ser desenvolvidas conforme fossem as características das cadeias? e (2) O alinhamento, a integração, a cooperação e a gestão individual, conforme as necessidades do conjunto das empresas, constituirão sempre a melhor alternativa para todas as empresas (e para cada uma das empresas) na cadeia?

Os problemas principais identificados em uma parte da literatura sobre GCS são: (1) a proposição da abordagem única de GCS, bastante apoiada nos pressupostos apresentados, o que pode ser verificado especialmente na literatura de cunho prescritivo; e (2) a apresentação de casos de cadeias de suprimentos, em que o modelo é apresentado como referência única de avaliação. Desse modo, quando os pressupostos, princípios e práticas 


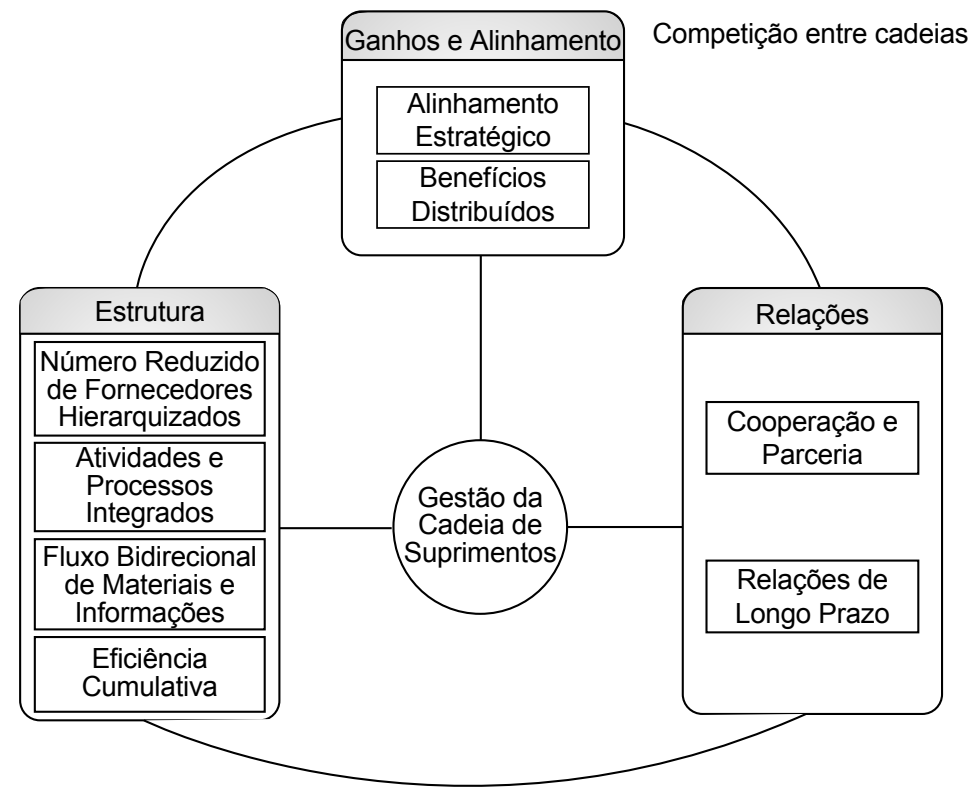

Figura 1. A GCS e seus pressupostos (elaborada pelos autores).

são adotados, à cadeia é atribuída uma avaliação positiva; quando não são adotados, a avaliação é negativa.

\section{Evidências empíricas na indústria au- tomobilística}

Esta seção visa ilustrar, partindo de evidências empíricas, em que medida os pressupostos da GCS podem ser verificados na prática. Para tal, procurou-se identificar na literatura estudos que apresentassem casos sobre cadeias de suprimentos das indústrias automobilísticas européia, americana e brasileira. Preferiu-se abordar a indústria japonesa apenas quando houvesse artigos comparando características desta indústria com as da indústria ocidental. Tal opção foi feita de modo a respeitar o espaço delimitado para este artigo e porque, com maior probabilidade, pesquisadores brasileiros irão analisar casos de cadeias comandadas por empresas automobilísticas instaladas no ocidente.

Os artigos aqui analisados relatam pesquisas empíricas que podem ilustrar características de cadeias de suprimentos relacionadas aos pressupostos da GCS previamente abordados. Esta breve revisão mostra, conforme apresentado a seguir, que os pressupostos da GCS podem ser confirmados empiricamente apenas parcialmente nas cadeias de suprimentos.

\subsection{Indústria européia}

Zirpoli e Caputo (2002) apresentam o processo de reestruturação de fornecedores da FIAT Italiana, que decorreu de uma política de outsourcing praticada pela montadora durante a década de 90 . Diferentemente do pressuposto de que deve haver somente competição entre cadeias e não mais entre empresas isoladas, o referido artigo apresenta a necessidade da FIAT estimular certa competição entre fornecedores, de forma a evitar possíveis riscos e ineficiências que poderiam advir de relacionamentos estritamente cooperativos.

O estudo empírico de Zirpoli e Caputo (2002) indica que uma configuração de relacionamento cooperativo entre empresas ocorre de modo limitado na cadeia. A ocorrência de benefícios para todos os integrantes da rede também não pôde ser verificada, pois, segundo os autores, a falta de técnicas de compartilhamento de lucros consistentes com os riscos assumidos pelos fornecedores ameaça sua motivação, sua atitude cooperativa e sua vontade de continuar a investir e assumir riscos.

Pérez e Sánchez (2001) desenvolveram uma pesquisa abrangendo 28 fornecedores na região de Aragão - Espanha -, com a finalidade de verificar, qualitativamente, $o$ nível de difusão das características que marcam as parcerias estratégicas. Os resultados apontam que apenas uma minoria das empresas estudadas envolveu-se no desenvolvimento de componentes de seus clientes e nenhuma envolveu seus fornecedores no desenvolvimento de produtos. Segundo os autores, isto denota um grau limitado de integração tecnológica, pois em países como EUA e Japão cerca de 25 a $50 \%$ das empresas estariam envolvidas no desenvolvimento de componentes.

Towill, Childerhouse e Disney (2002) analisaram 20 cadeias automotivas européias e concluíram que 11 dessas cadeias teriam atingido um estágio de integração funcional e, portanto, poderiam ser consideradas como cadeias que possuem processos enxutos, que serviriam 
como base para sua evolução ao estágio mais avançado de integração interna. Cerca de $20 \%$ estariam exibindo um conjunto de boas práticas, mas cerca de $70 \%$ estariam em estágios de transição, ainda distantes do que os autores construíram como modelo de referência.

Doran (2001) analisou o caso do fornecimento sincrônico de bancos por um fornecedor de assentos a uma montadora, ambos instalados no Reino Unido. Conclui que o sucesso de tal prática depende da existência de relações estreitas entre fornecedor e montadora, mas que, dadas as dificuldades envolvidas em tal desenvolvimento, este sistema de fornecimento teria de estar restrito a um pequeno número de componentes chave.

Estudos empíricos na indústria automobilística da Suécia indicam que altos ou satisfatórios níveis de confiança, entre compradores e fornecedores, resultam em cadeias de suprimentos "lean" (enxutas), "responsive" (que atendem rapidamente novas necessidades) e "agile" (ágeis) (Svensson, 2001). O survey envolveu 229 empresas e 458 executivos foram entrevistados.

Doran (2004) ainda acrescenta que a modularização fortalece a tendência de organização em níveis (camadas) e de diminuição do número de fornecedores em cada cadeia.

\subsection{Indústria americana}

O trabalho de Brunnermeier e Martin (2002) analisa os custos originados por problemas e incompatibilidades no fluxo de dados relativos a produtos, chamados custos de interoperabilidade. Como reflexo do fluxo ineficiente de dados na cadeia, estima-se que os custos de interoperabilidade na automobilística americana sejam de 1 bilhão de dólares ao ano, dos quais $90 \%$ são para corrigir problemas, e não para evitá-los. Os autores ressaltam ainda os diferentes impactos que estes custos podem ter ao longo da cadeia, dado que para fornecedores menores, em níveis mais afastados da cadeia, tais custos podem representar $12 \%$ da receita anual.

A existência de benefícios para todas as empresas da rede parece não haver sido verificada em Lauer (2000). Em seu artigo, o autor analisou os efeitos colaterais da adoção forçada de EDI, que as "Big 3" americanas (Chrysler, Ford e GM) impuseram sobre seus fornecedores. Segundo o autor, a adoção obrigatória do $E D I$ refletiu a enorme diferença de poder existente entre os elos da cadeia, e que a lógica adotada foi a de "o que é bom para a cadeia de suprimentos é bom para o setor industrial, e isso significa bom para as Big 3".

Dyer, Cho e Chu (1998) mostram que as empresas podem utilizar simultaneamente dois modelos de gestão de suprimentos, arms-lenght (modelo tradicional) e parcerias, em uma pesquisa empírica comparando as relações entre montadora e fornecedores da indústria automobilística dos Estados Unidos, Japão e Coréia. Nos EUA as relações estão se aproximando dos modelos de parcerias. Na Coréia, predominam as relações do modelo tradicional. Já no Japão observam-se os benefícios de ambos, com fornecedores segmentados em dois grupos: 1) fornecedores de inputs estratégicos (gerenciados por parcerias); e 2) fornecedores de inputs não estratégicos (arms-lenght).

Bensaou (1999), como resultado de sua pesquisa empírica envolvendo gerentes das três empresas americanas e onze japonesas, observou que as parcerias estratégicas são menos evidentes entre firmas japonesas do que entre as americanas. Na indústria automobilística japonesa predominam os casos dos "fornecedores cativos", em que os fornecedores fazem investimentos em ativos específicos (para a relação com cada montadora) maiores do que os investimentos correspondentes realizados pelas montadoras.

Tan (2002) investigou nos EUA a viabilidade das práticas de GCS por meio de um survey. Os resultados indicam que dois terços das empresas praticam alguma forma de GCS. A conclusão é a de que a GCS tem impacto positivo no desempenho empresarial.

\subsection{Indústria brasileira}

Lima (2004) ressalta que a T.I. (Tecnologia de Informação) é uma ferramenta importante para o aumento e para a melhoria do fluxo de informações e materiais. Seu artigo procura embasar um dos pressupostos contidos neste trabalho: a existência de fluxo bidirecional de produtos (materiais e serviços) e de informação entre todas as empresas pertencentes à cadeia.

Em relação à existência de fluxo bidirecional de produtos (materiais e serviços) e de informação entre todas as empresas nas cadeias, a pesquisa de Salerno et al. (2001) constata que esta prática é difundida no setor, viabilizada pela comunicação por meio eletrônico. Mostra também que o fornecimento de módulos, sistemas e subconjuntos é uma realidade no setor, pois cerca de $39 \%$ das empresas pesquisadas adotam tais práticas. Quanto aos compromissos de longo prazo, a pesquisa aponta que as empresas mantêm compromissos por períodos relativamente longos, apoiados por contratos formais estabelecidos por prazo maior do que 1 ano. Cerca de $69 \%$ das empresas da amostra adotam tais práticas. A pesquisa de Salerno et al. (2001) mostra que as estruturas das cadeias e as relações entre empresas evoluíram no sentido propugnado pela GCS.

Alves Filho et al. (2001) e Sacomano Neto (2004) fornecem indícios de que as estruturas das cadeias condicionam as relações entre empresas e de que estruturas e relações condicionam as práticas na cadeia. Os estudos também indicam que as relações entre montadoras e fornecedores variam e dependem das características diferenciadas dos fornecedores.

O estudo de Sacomano Neto (2004), envolvendo duas 
montadoras de caminhões e ônibus e dois fornecedores de autopeças, mostra que o sistema modular estimulou a redução e a hierarquização dos fornecedores de autopeças participantes da cadeia. Revela que as trocas de informações, de produtos, e as interações para coordenação e controle estimularam a difusão de conhecimento na montadora e nos fornecedores envolvidos no sistema modular. A pesquisa mostra, ainda, que nos casos estudados nem sempre os benefícios são compartilhados entre os atores participantes, em função da assimetria de poder entre as montadoras e as autopeças. A assimetria de poder é mitigada no caso das relações entre montadoras e fornecedores de sistemas e módulos, que ocupam posições privilegiadas na estrutura da rede e que assim ampliam sua capacidade de negociação. Mas os modulistas também estão sujeitos a diversas formas de controle altamente institucionalizadas.

No arranjo modular estudado, a montadora estabeleceu com precisão os papéis dos modulistas quanto às atividades manufatureiras, quanto ao aperfeiçoamento dessas atividades e das atividades de design dos componentes, e quanto às atividades de acompanhamento das entregas e da qualidade dos fornecedores do nível 2,0. A montadora mantém a administração das compras de componentes provenientes do nível 2,0 (Alves Filho et al., 2003).

O caso da cadeia de motores (Alves Filho et al., 2003) evidencia que os papéis dos fornecedores e as relações que mantêm com a montadora de motores são muito diferentes em função de características tais como porte, origem do capital, capacidade tecnológica, dentre outros. O caso mostrou, também, que iniciativas de desenvolvimento e apoio tecnológico e de qualidade por parte da montadora podem estar perfeitamente de acordo com seus interesses estratégicos (de terceirização e de controle da cadeia) ao visar retornos maiores e maior poder de barganha. Do ponto de vista dos fornecedores de pequeno porte e controlados pela montadora, a alternativa de fornecimento subordinado à montadora pode significar, eventualmente, a melhor alternativa de posicionamento estratégico no setor automobilístico e abrir oportunidades de fornecimento a outras montadoras no futuro.

Resumindo, os estudos empíricos na Europa, EUA e Brasil indicam que as possibilidades de alinhamento estratégico e de propensão a posturas de repartição equânime dos ganhos (que caracterizariam relações simétricas de poder) são limitadas, mesmo nos casos dos fornecedores principais (multinacionais), pois estes, em geral, atendem, simultaneamente, vários clientes-montadoras e, exceto no caso das unidades dedicadas (na manufatura celular ou nos condomínios industriais) e dos relacionamentos de mais longo prazo, não possuem as motivações que às vezes são deduzidas na literatura sobre GCS. Já os fornecedores nacionais e de menor porte ficam, em geral, sob controle das montadoras, mas não se pode afirmar que as relações aí sejam cooperativas e simétricas. A assimetria de poder é o que marca essas relações.

Pode-se afirmar que as montadoras procuram exercer um papel de coordenação na cadeia - e o mesmo pode ser dito sobre alguns de seus principais fornecedores multinacionais - e isso tende a ser para elas vantajoso. A coordenação direta da montadora sobre sua cadeia, embora se estenda em alguns casos até os fornecedores no nível 2,0 e seja reforçada por mecanismos de coordenação indireta como no caso da certificação de normas de qualidade, é limitada em razão de três fatores. Primeiro, pela estrutura da cadeia, pois logo no nível 1,0 estarão fornecedores fortes (multinacionais proprietárias de tecnologia) que atendem diversas montadoras e exercem certo controle sobre seus próprios fornecedores. Além disso, em estruturas com fornecedores no primeiro nível não exclusivos, o compartilhamento de atividades tecnológicas é também (estrategicamente) limitado. Segundo, porque muitos dos fornecedores no segundo nível produzem componentes para outros setores econômicos, em que pese a importância econômica do setor automobilístico. Terceiro, porque nos níveis 3,0 ou 4,0 estão posicionadas empresas multinacionais fornecedoras de matérias-primas em setores oligopolizados, com grande poder de barganha a jusante e menos propensas à adoção de práticas orientadas pelo modelo da produção enxuta.

Na seção a seguir, são apresentadas algumas correntes teóricas que podem contribuir para o desenvolvimento e sistematização de uma etapa metodológica inicial, para a análise das cadeias de suprimentos.

\section{Outras correntes de pensamento sobre cadeias de suprimento}

Diversos aspectos incluídos nos pressupostos apresentados são abordados por outras correntes de pensamento e linhas de pesquisa nas áreas de Organização Industrial, Economia Institucional e Sociologia Econômica. Sem pretender considerar todas as alternativas, três dessas correntes foram escolhidas para ilustrar como poderiam subsidiar a discussão e eventual verificação dos pressupostos apresentados. São elas: a Análise das Redes, a Dependência de Recursos e a Economia dos Custos de Transação. Estas perspectivas teóricas, segundo Trienekens (1999), pertencem à linha institucional.

\subsection{Análise das redes}

A perspectiva das redes vem influenciando muitos estudos no âmbito da estratégia e da teoria das organizações, e particularmente a GCS. A Análise das Redes pode contribuir de diversas formas à Gestão da Cadeia de Suprimentos, principalmente quanto aos aspectos morfológicos e ao posicionamento estrutural e relacional que um ator pode ocupar em uma determinada rede. 
Como mencionado por Lambert, Cooper e Pagh (1997), uma das questões chave para a GCS é o entendimento de como a estrutura da rede é configurada. Para isto, os autores definem três aspectos chave: 1) mapear quem são os membros da cadeia; 2) as dimensões estruturais da rede; e 3) os diferentes tipos de processo que atravessam a cadeia. A análise das redes auxilia a compreensão da "força" relativa de cada membro, ou de um conjunto de membros, em uma estrutura de relações de troca. Como mencionado por Pires (2004: 52), "a lógica da rede remete-nos a uma estrutura mais complexa em que, raramente, existe uma linearidade na execução dos processos e/ou atividades".

A rede, como instrumento de análise, apóia-se na estrutura das relações para compreender uma ampla gama de aspectos. Nessa perspectiva, o ambiente social pode ser expresso como estruturas ou relações regulares entre as unidades (Wasserman e Faust, 1994).

Conforme mencionado por Britto (2002), existem quatro elementos morfológicos que constituem a estrutura das redes: nós, posições, ligações e fluxos.

Os nós podem ser descritos como um conjunto de agentes, objetos ou eventos presentes na rede em questão. Existem duas perspectivas para o estabelecimento dos nós da rede: a primeira tem as empresas como unidade básica de análise e a segunda considera as atividades como os pontos focais do arranjo.

As posições definem as localizações das empresas ou atividades (os nós) no interior da estrutura. Segundo Granovetter (1985), existem dois tipos de posicionamentos na rede (embeddedness): o estrutural e o relacional. O primeiro enfatiza como a posição estrutural de um ator na rede afeta o seu comportamento, e o segundo enfatiza a dependência do comportamento dos atores com a estrutura de mútuas expectativas. Na estrutura estão presentes a relação de poder, a confiança, o oportunismo, o controle social, os sistemas de alinhamento de interesses, as formas de negociação e as formas de seleção de fornecedores, dentre outros aspectos.

As ligações, conexões ou linkages, determinam o grau de interconexão dos atores de uma rede. Britto (2002) destaca que é necessário um detalhamento dos relacionamentos organizacionais, produtivos e tecnológicos entre os membros da rede. Para o entendimento da estrutura de uma rede, ainda é necessária a análise dos fluxos tangíveis (insumos e produtos) e dos intangíveis (informações). A estrutura contém canais por meio dos quais os atores trocam bens e serviços, transferem recursos e informações. Essas trocas qualificam a relação entre os atores.

A morfologia das redes ajuda a ampliar a compreensão a respeito da estrutura e das relações, entre os atores produtivos participantes de uma determinada cadeia. A compreensão de como as empresas se posicionam na estrutura da rede e como estabelecem os diversos vínculos são aspectos essenciais para o entendimento da dinâmica da Gestão da Cadeia de Suprimentos.

Pressupostos da GCS podem ganhar novas interpretações com a Análise das Redes. Tanto a morfologia como os diversos posicionamentos na estrutura auxiliam a explicar as vantagens competitivas de membros que ocupam posições privilegiadas na estrutura de uma rede. Posições privilegiadas na estrutura da rede podem implicar em acesso a recursos, informações, matérias-primas, entre outros aspectos. Nesse sentido, a análise das redes ajuda a explicar como a competição configura-se entre cadeias e não mais entre empresas isoladas. A competição entre cadeias pode levar a uma concentração ou, até mesmo, a uma hierarquização dos fornecedores, como vem ocorrendo na indústria de autopeças no Brasil.

Outros pressupostos da GCS, como a coordenação e o planejamento das atividades e processos, a configuração de relacionamentos cooperativos e a existência de compromissos de longo prazo são aspectos que estão no centro das preocupações da Análise das Redes, pois são fundamentais para qualificar uma relação colaborativa. Este nível de análise está relacionado à presença de confiança, reputação e reciprocidade, os quais interferem nos mecanismos da GCS.

\subsection{Dependência de recursos}

A Dependência de Recursos considera que o ambiente exerce uma forte influência nas organizações e concentra a análise no fluxo de recursos críticos e escassos. Possui fortes laços com a economia política das organizações (Hall, 1990) e com a sociologia (Nohria e Gulati, 1994), tendo em sua raiz o trabalho de Pfeffer e Salancik (1982). Nesse trabalho, os autores destacam que a Dependência de Recursos tem recebido maior atenção desde que se percebeu que as organizações controlam e alteram as atividades umas das outras e que podem desenvolver mecanismos para minimizar sua vulnerabilidade e dependência ambiental.

A Dependência de Recursos considera ativo o processo de interação com o ambiente (Hall, 1990). As organizações tentam manipular o ambiente em que atuam em seu próprio beneficio, tomando decisões estratégicas para melhor se adaptarem a ele. Sendo variados os tipos de recursos - novas tecnologias, matérias-primas, recursos financeiros, políticos, entre outros - é complexo o processo de tomada de decisão sobre as ações que visam ampliar o controle ou sobre aquelas, de caráter preventivo, que antecipam decisões ligadas aos recursos escassos, denominadas, por Hatch (1997), como ações de contradependência.

A contribuição dessa perspectiva é relevante no que diz respeito às relações inter-organizacionais (Hall, 1990) e, também, para a compreensão das forças de poder e dependência existentes na rede de relações inter-or- 
ganizacionais (Hatch, 1997). As organizações usam a interação ambiental como um recurso capaz de minimizar os problemas ligados à interdependência e às incertezas do ambiente (Pfeffer, 1972). Tentam absorver a interdependência e as incertezas, seja por meio de fusões e aquisições, seja por meio da cooperação entre organizações e da troca de recursos ou, até mesmo, pela troca entre profissionais da organização. As unidades organizacionais que têm capacidade para interagir com as restrições, incertezas e contingências do ambiente também obtêm maior poder dentro das organizações (Hall, 1990).

A dependência entre organizações reflete a diferença de poder entre elas, pois uma organização tem mais ou menos poder, em relação às outras, à medida que controla os recursos necessários pelas outras ou reduz sua própria dependência, por meio do controle dos recursos (Nohria e Gulati, 1994).

A Dependência de Recursos pode ser, assim, útil para compreender como as organizações tentam minimizar sua dependência em relação a outras organizações, na cadeia de fornecimento. Uma organização pode alterar ou se adaptar aos relacionamentos interdependentes ao adotar estratégias de recursos (Daft, 1999) que podem resultar na aquisição da propriedade dos fornecedores, na elaboração de contratos e parcerias para assegurar recursos, etc. As associações de negócios, acordos, fusões, cooperação, ações políticas e lobbies são formas de ações para lidar com as diversas dependências de recursos a que os atores produtivos estão sujeitos.

A Dependência de Recursos também ajuda a compreender as assimetrias de poder presentes nas cadeias de suprimento. Quando uma empresa tem poder sobre outra, pode exigir dos fornecedores a absorção de mais custos, a expedição de suprimentos com maior eficiência e o fornecimento de mais serviços do que antes, muitas vezes sem aumentar os preços (Daft, 1999). Isto não é o mesmo que admitir que as relações são simétricas, como pressupõe a GCS. Diversos estudos no âmbito da Análise das Redes e da Dependência de Recursos tratam das questões relativas ao poder. As relações assimétricas de poder podem levar um ator mais poderoso a determinar diversas condições a outros atores desfavorecidos na estrutura de uma cadeia. Por esse fato, Amato Neto (2000) denomina o setor automobilístico de uma "rede vertical de produção".

A ocorrência de número reduzido de fornecedores, hierarquizados de acordo com o nível que ocupam na cadeia, entendido como pressuposto da GCS, pode ser compreendida com mais profundidade a partir da perspectiva da Dependência de Recursos, pois quanto maior a interdependência dos atores, maiores serão suas dependências e troca de recursos. Os mecanismos de coordenação da Cadeia de Suprimentos são influenciados pelos recursos de poder que podem ser econômicos, tecnológicos, conheci- mento, confiança e reciprocidade (Trienekens, 1999)

A perspectiva da dependência de recursos também possibilita melhor compreensão sobre as formas e alternativas, para o alinhamento de estratégias competitivas das empresas participantes da cadeia e a existência, ou não, de compromissos de longo prazo entre fornecedores e clientes, constituindo uma abordagem que pode complementar a análise de cadeias de suprimentos.

\subsection{Economia dos custos de transação}

A ECT, uma ramificação da Economia Institucional, considera as transações como a unidade básica de análise (Trienekens, 1999) e estuda, em linhas gerais, como parceiros em uma transação protegem-se dos riscos associados às relações de trocas.

Fatores ambientais (especificidade dos ativos, incerteza e a frequiência com que as transações ocorrem) e comportamentais (racionalidade limitada e oportunismo) afetam os custos de transação (Williamson, 1985). Mais especificamente: a) ativos específicos: são ativos que não são reempregáveis a não ser com perdas de valor; b) incerteza: o papel que a incerteza representa é o de revelar os limites da racionalidade, sendo resultante da assimetria informacional; c) freqüência das relações: a repetição de uma mesma espécie de transação possibilita que as partes envolvidas adquiram conhecimento umas das outras (reduzindo incerteza); d) racionalidade limitada: considera-se que os indivíduos agem racionalmente, mas de modo limitado; e e) oportunismo: considera-se que não há restrições ao comportamento egoísta dos agentes econômicos, o que implica dizer que as partes podem se aproveitar de uma negociação, impondo perdas à(s) sua(s) contraparte(s) na transação.

A ECT explora os custos econômicos associados às estruturas de governança requeridas para completar a transação, prevendo que a forma organizacional que minimiza custos de transação será escolhida (Mcnally, 2002).

Uma estrutura de governança consiste em um mecanismo usado pelas firmas com a finalidade de atenuar a ameaça de oportunismo. Economistas vêm conceituando estruturas de governança considerando três tipos principais, sendo que o método para determinar a eficiência de cada uma delas consiste em examinar os custos de transação envolvidos (Barney, 1999): a) mercado: transações nas quais ocorre uma instantânea transferência de produtos ou serviços e que os preços são determinados pelo mercado; b) integração vertical (hierarquia): mecanismo utilizado para gerenciar trocas econômicas dentro das próprias fronteiras da firma; e c) híbrida: franchises e alianças estratégicas são exemplos que combinam aspectos de transações de mercado e integração vertical.

Assim, a principal hipótese que a ECT trabalha, segundo Williamson (1994), é o alinhamento de transações (diferentes em seus atributos) com estruturas de gover- 
nança (diferentes em seus custos e competências). Considera-se, por exemplo, que, conforme a especificidade dos ativos aumenta, mais complexas são as estruturas de governança, ou seja, contratos mais complexos são requeridos para atenuar barganhas sobre lucros de ativos específicos (Williamson, 1985) e, portanto, maiores são os custos de transação.

A ECT tem como ponto de partida, segundo Stern apud Trienekens (1999), a análise de decisões do tipo make or buy, ou seja, a decisão entre produzir internamente ou terceirizar. A extensão em que se realiza a terceirização (outsourcing) depende dos custos de transação envolvidos.

A peculiaridade da análise de Williamson (1996) está em promover a centralidade dos custos de transação em lugar dos custos de produção. Como ressaltado por Scott apud Hall (1990), a perspectiva do custo de transação assume que o que é crítico não é a produção, mas, sim, o intercâmbio de bens e serviços e as estruturas que governam estes intercâmbios.

A abordagem da ECT pode ser utilizada para avaliar a qualidade e a riqueza das relações entre compradores e vendedores e o valor do desenvolvimento de parcerias e confiança entre eles. A ECT considera as implicações das escolhas organizacionais em desenvolver uma transação ou atividade internamente ou no mercado e auxilia a avaliar como vários tipos de investimentos com outras firmas podem contribuir para a formação de capacidades de longo prazo.

Assim, a ECT, enquanto perspectiva teórica que pode auxiliar pesquisas em cadeias de suprimentos, considera que economias de custos de transação podem ser alcançadas nas relações entre empresas, comparando os custos de se manter relacionamentos contínuos com aqueles custos relacionados ao procurement, avaliação, seleção e desenvolvimento de habilidades de novos fornecedores.

A configuração de relacionamento cooperativo ou de colaboração entre as empresas, sugerida pela teoria de GCS, pode ser estudada sob a ótica dos elementos de ECT: quando os parceiros envolvidos em uma transação investem em ativos específicos, e o relacionamento passa a se basear em uma dependência mútua, reduzem-se os incentivos de cada parte ao oportunismo e tem-se a eficiência em custos de transação como motivação para a cooperação (Ojode, 2000). Grant e Baden-Fuller (2000) sugerem outro benefício da cooperação, além da minimização dos custos de transação, como a criação de um contexto organizacional capaz de suportar mecanismos de integração de conhecimento.

Outro pressuposto da GCS, como já mencionado, é a existência de compromisso de longo prazo entre fornecedores e clientes. Os estudos de ECT indicam que a repetição de uma mesma espécie de transação leva à construção de reputação por parte dos agentes envolvi- dos, possibilitando que as partes adquiram conhecimento umas das outras, reduzindo as incertezas envolvidas (Farina, Azevedo e Saes, 1999). Os benefícios das relações de longo prazo surgem, segundo Swaminathan, Hoetcker e Mitchel (2002), de três fatores relacionados: o desenvolvimento do conhecimento de cada parceiro, o desenvolvimento de confiança e relações baseadas em rotinas específicas.

Estabelecimento de contratos formais entre empresas da cadeia, outro pressuposto de GCS, é um tema bastante explorado em ECT. Pela racionalidade limitada dos tomadores de decisão, a distribuição assimétrica de informação e a inabilidade de especificar completamente o comportamento dos agentes na presença de múltiplas contingências, a ECT considera que todos os contratos são incompletos e, portanto, sujeitos a renegociações e a ocorrência eventual de comportamento oportunista (Leiblein e Miller, 2003).

Quando duas partes ou mais realizam investimentos específicos e surge uma situação de dependência mútua, haverá incentivos para que o contrato não seja rompido e continue indefinidamente ou por um tempo pré-determinado (Scramin, 2003).

Ao abordar as relações entre empresas, a ECT enfatiza a importância da confiança nos relacionamentos, tema que não tem sido tratado pela GCS. Confiança em relações entre comprador e fornecedor pode ser importante fonte de vantagem competitiva porque (Grover e Malhotra, 2003): a) proporciona menores custos de transação; b) facilita investimentos em relações que envolvem ativos específicos; e c) leva a rotinas de troca de informações. Confiança pode substituir controles formais e contratos.

A Tabela 1 resume as correntes alternativas de pensamento citadas nesta seção, apresentando o nível de análise, as principais variáveis e as contribuições de cada uma à GCS.

As perspectivas apresentadas sugerem a necessidade de observar aspectos críticos da cadeia de suprimentos, como a estrutura e as relações entre os atores, a dependência e o fluxo de recursos críticos e as transações estabelecidas entre os atores. Essas perspectivas, combinadas à GCS, podem contribuir para melhor compreensão dos comportamentos existentes e dos resultados obtidos por empresas e unidades produtivas envolvidas em cadeias de suprimentos.

\section{Considerações finais}

Em nossa percepção, é extremamente importante a continuidade da discussão sobre o conjunto de pressupostos da GCS, pois estes interferem diretamente na natureza do conhecimento que pode ser adquirido e acumulado, seja pela via teórico-dedutiva, seja pela empírico-indutiva nas pesquisas nessa área. A literatura empírica, apreciada 
Tabela 1. Síntese das correntes alternativas de pensamento apresentadas.

\begin{tabular}{lcll}
\hline & Foco & \multicolumn{1}{c}{ Principais variáveis } & \multicolumn{1}{c}{ Contribuições a GCS } \\
\hline $\begin{array}{l}\text { Análise das } \\
\text { redes }\end{array}$ & $\begin{array}{l}\text { Estrutura e rela- } \\
\text { ções dos atores } \\
\text { da rede }\end{array}$ & $\begin{array}{l}\text { Posição estrutural e relacional } \\
\text { na rede, natureza das relações, } \\
\text { nós, fluxo de recursos e rela- } \\
\text { ções de poder. }\end{array}$ & $\begin{array}{l}\text { Identificar posições privilegiadas dos atores na estru- } \\
\text { repercutir em acesso a recursos, informações, matérias } \\
\text { primas; configuração ou não de relacionamentos coope- } \\
\end{array}$ \\
& & $\begin{array}{l}\text { rativos (qualificar uma relação cooperativa); a existência } \\
\text { de compromissos de longo prazo e dinâmica ou estabili- } \\
\text { dade da cadeia produtiva. }\end{array}$
\end{tabular}

Dependência de Dependência de Fluxo de recursos críticos e recursos recursos entre organizações

Economia dos Transações custos de transação escassos, interdependência, estratégias de recursos e relações de poder.

Racionalidade limitada e comportamento oportunista para explicar a existência de custos de transação. De acordo com a importância de cada elemento, um mecanismo é escolhido dentre as formas de coordenar uma transação - mercado spot, hierarquia ou formas híbridas.
Estratégias de recursos podem gerar colaboração e/ou competição entre os atores; compreensão de assimetrias de poder na cadeia produtiva; grau de interdependência dos atores na cadeia, alinhamento de estratégias e recursos entre os atores.

Avaliar a Qualidade e riqueza das relações entre comprador e vendedor - considerando a freqüência das relações, as incertezas envolvidas, especificidade dos ativos e assimetria de informações;

Escolhas organizacionais em desenvolver uma transação (ou atividade) internamente, por meio de alianças ou no mercado;

Auxilia a avaliar como vários tipos de investimentos com outras firmas podem contribuir para a formação de capacidades de longo prazo. neste trabalho, mostra que a GCS vem sendo amplamente difundida e que há uma tendência das organizações e das cadeias de organizações a adotarem diversas das práticas da GCS, explorando os espaços de aumento da eficácia e eficiência das cadeias de suprimentos. Indica, entretanto, que os pressupostos, quanto às cadeias, podem ser apenas parcialmente verificados, ou verificados em apenas alguns segmentos das cadeias no setor automobilístico. Faz-se necessário, então, que novas pesquisas venham a fornecer subsídios que possam elucidar as questões aqui mencionadas.

Nossa discussão nos leva a sugerir que as abordagens de GCS devem incluir uma etapa inicial de "verificação dos pressupostos", ou de identificação da configuração da cadeia de suprimentos, pois, por meio desta, poderiam ser desvendados os tipos de contextos em que as relações entre as empresas e a GCS poderiam se desenvolver. Seria evitada, assim, a "armadilha" da aceitação incondicional dos pressupostos e das decorrentes práticas de GCS, refutando-se, conseqüentemente, a existência de uma abordagem única, adequada a qualquer situação.

O conjunto dos pressupostos, segundo nossa análise, pode ser subdividido em quatro categorias: (1) competição entre cadeias (2) alinhamento estratégico e repartição de ganhos, (3) estrutura hierarquizada e integrada, e (4) relações cooperativas e de longo prazo.

Quanto à competição entre cadeias, a literatura mostra que no setor automobilístico tal lógica não pode ser integralmente utilizada, embora as montadoras exerçam um papel (limitado) de coordenação e procurem obter vantagens competitivas de suas cadeias de suprimentos.
Quanto ao alinhamento estratégico, nossa revisão indica que uma empresa pode fazer parte simultaneamente de diferentes cadeias, atendendo clientes situados em diferentes setores ou, até mesmo, clientes concorrentes de um mesmo setor. Os ganhos serão distribuídos conforme forem a distribuição do poder entre os participantes, a estrutura da cadeia e as relações estabelecidas entre as empresas.

A possibilidade de alinhamento dos negócios das empresas envolvidas em uma cadeia e o exercício de seus papéis na cadeia, tanto para a produção e distribuição de bens e serviços quanto para a coordenação e distribuição dos ganhos, depende da estrutura da cadeia e da avaliação dos possíveis benefícios e das dificuldades de sua modificação. Os papéis nas cadeias poderão, ou não, ser melhor distribuídos e exercidos, dependendo também do poder de coordenação dos participantes, especialmente daqueles que comandam o projeto e a produção dos produtos finais, e das relações entre os atores com maior poder.

Estritamente vinculada às condições acima, a estrutura da cadeia contempla os papéis, portes, capacidades de produção, produtos e serviços fornecidos, direcionamento setorial e empresarial desses produtos e serviços, competência tecnológica, etc., abarcando alguns dos fatores que condicionam (e também são condicionados por) o alinhamento das estratégias, a coordenação das ações e as relações entre as organizações.

Finalmente, poderá haver maior ou menor integração funcional (entre organizações) e integração dos processos na cadeia e, ainda, maior ou menor possibilidade de coordenação (centralizada ou não) conforme se caracte- 
rizarem as relações entre empresas na cadeia. Estas poderão ser cooperativas e de longo prazo, ou conflituosas e de curto prazo, com maior ou menor compartilhamento de informações e com uma gestão mais ou menos transparente e integrada.

Estas considerações sobre os pressupostos da GCS são ainda preliminares, mas nos levam a sugerir que os estudos empíricos sobre cadeias de suprimentos passem a implementar uma etapa metodológica inicial que contemple a identificação das características principais estruturais e relacionais da cadeia e que constituem o contexto em que os princípios e as técnicas da GCS poderão ser implementados, adequando-se às finalidades, características e modos de repartição de ganhos de cada cadeia.

A consecução de tal etapa metodológica pode ser atingida com a utilização de proposições de outras correntes de pensamento que vêm focalizando o mesmo objeto. Como ilustrado aqui, a Teoria das Redes, a Teoria sobre Dependência de Recursos e a Economia de Custos de Transação adotam uma perspectiva institucional na análise das cadeias, ao focalizarem as possibilidades de conexão, as formas de coordenação das cadeias e também o ambiente institucional (Trienekens, 1999). Desta forma, oferecem elementos que auxiliam a compreensão das características estruturais e relacionais das cadeias de suprimentos e de como essas características podem evoluir.

\section{Referências Bibliográficas}

ABDALA, E. C. Investigação e análise estratégica do processo de seleção de fornecedores quanto ao estabelecimento de relações de parceria. 2002. Dissertação (Mestrado em Engenharia de Produção) - Escola de Engenharia de São Carlos, Universidade de São Paulo, São Carlos, 2002.

ALVES FILHO, A. G. et al. O consórcio modular e seus impactos na cadeia de suprimentos da fábrica de motores VW-São Carlos. São Carlos, Processo FAPESP 97/13071-9, 2001.

ALVES FILHO, A. G. et al. Estratégias de produção em cadeias de suprimentos: dois casos na indústria automobilística. In: ENCONTRO NACIONAL DE ENGENHARIA DE PRODUÇÃO. Ouro Preto, 2003. Anais... Ouro Preto: ENEGEP, 2003.

AMATO NETO, J. Redes de cooperação e clusters competitivos. São Paulo: Atlas, 2000. 163 p.

BALLOU, R. H. Gerenciamento da cadeia de suprimentos. Planejamento, Organização e Logística empresarial. 4. ed. Porto Alegre: Ed. Bookman, 2001. 532 p.

BARNEY, J. B. How a firm's capabilities affect boundary decisions. Sloan Management Review. v. 40, n. 3, p.137-145, Spring, 1999.

BAUM, J. A. C.; DUTTON, J. E. (Org.) Advances in strategic management: the embeddedness of strategy. New York: Elsevier Science, 1996. 430 p.

BENSAOU, M. Portfolios of buyer-supplier relationships. Sloan Management Review, v. 41, n. 4, p. 35-44, Summer, 1999.

BOWERSOX, D. J.; CLOSS, D. J. Logistical management: the integrated supply chain process. $1 \mathrm{ed}$. Estados Unidos: Mc Graw-Hill, 1996.

BRITTO, J. Redes de cooperação entre empresas. In: KU-
PFER, D. Economia industrial: fundamentos teóricos e práticas no Brasil. Rio de Janeiro: Editora Campus, p. 345-386, cap. 15, 2002.

BRUNNERMEIER, S. B.; MARTIN, S. A. Interoperability costs in the US automotive supply chain. Supply Chain Management: An International Journal, v. 7, n. 2, p. 71-82, 2002.

CHRISTOPHER. M. Logística e gerenciamento da cadeia de suprimentos. São Paulo: Ed. Pioneira: 1997. 240 p.

COOPER. M, LAMBERT. D.; PAGH, J. Supply chain management more than a new name for logistics. International Journal of Logistics Management. v. 8, n. 1, p. 1-14, 1997.

DAFT, R. L. Administração. Rio de Janeiro: Livros Técnicos e Científicos, 1999. 516 p.

DORAN, D. Synchronous supply: an automotive case study. European Business Review. v. 13, n. 2, p. 114-120, 2001.

Rethinking the supply chain: an automotive perspective. Supply Chain Management: an International Journal, v. 9, n. 1, p. 102-109, 2004.

DYER, J. H.; CHO, D. S. CHU, W. Strategic Supplier Segmentation: a model for managing supplier in the $21 \mathrm{st}$ Century. In: HAMEL, G.; PRAHALAD, C.K.; THOMAS, H.; et al. Strategic flexibility - managing in a turbulent environment. New York: John Willey \& Sons, 1998. $416 \mathrm{p}$.

FARINA, E. M.; AZEVEDO, P. F.; SAES, M. S. Competitividade: mercado, estado e organizações. São Paulo: Singular, 1999. 286 p.

GRANT, R. M.; BADEN-FULLER, C. Knowledge and economic organization: an application to the analysis of interfirm collaboration. In: VON KROGH, G.; NONAKA, 
I. NISHIGUCHI, T. Knowledge Creation: a source of value. New York: MacMillan Press, 2000, cap. 5.

GRANOVETTER, M. S. Economic action and social structure: the problem of embeddedness. American Journal of Sociology. v. 91, n. 4, p. 491-501, 1985.

GROVER, V.; MALHOTRA, M. Transaction cost framework in operations and supply chain management research: theory and measurement. Journal of Operations management, v. 21, n. 4, p. 457-473, 2003.

HALL, R. H. Desarrollos recentes en teoria organizacional: una revision. Ciencia y Sociedad, v. 15, n. 4, 1990.

HATCH, M. J. Organization theory. New York: Oxford University Press, 1997. 385p.

LAMBERT, D. M.; EMMELHAINZ, M. A.; GARDNER, J. T. Developing and Implementing Supply Chain Partnerships. The International Journal of Logistics Management. v. 9, n. 2, p. 1-17, 1996.

LAUER, T. W. Side effects of mandatory EDI order processing in the automotive supply chain. Business Process Management Journal. v. 6, n. 5, p. 366-375, 2000.

LEIBLEIN, M.J.; MILLER, D. An empirical examination of transaction-and firm-level influences on the vertical boundaries of the firm. Strategic Management Journal. v. 24, p. 839-859, 2003.

LIMA, J. C. de S. Um Estudo sobre a reconfiguração da função compras em empresas do setor automotivo. 2004. Tese (Doutorado em Engenharia de Produção). Escola Politécnica - Universidade de São Paulo, São Paulo, 2004.

LUMMUS, R. R.; VOKURKA, R. J.; ALBER, K. L. Strategic supply chain planning. Production and Inventory Management Journal. v. 39, n. 3, p. 49-58, 1998.

MCNALLY, R. C. Efficiency motives and institutional considerations in make-or-buy decisions. 2002. Thesis (Doctor of Philosophy in Business Administration), University of Illinois - Urbana-Champaign.

MCHUG, M; HUMPHREYS, P; MCLVOR, R. Buyer-supplier relationships and organizational health. The Journal of Supply Chain Management, v. 39, n. 2, p. 15-25, May 2003.

MIRANDA, J. L. Procedimento para análise da viabilidade da utilização de operadores logísticos na cadeia de suprimentos. 2002. $171 \mathrm{f}$. Tese (Doutorado em Engenharia de Produção) - Escola de Engenharia de São Carlos, Universidade de São Paulo, São Carlos, 2002.

NEW, S. J. A framework for analysing supply chain improvement. International Journal of Operations \& Production Management. v. 16, n. 4, p. 19-34, 1996.

NOHRIA, N.; GULATI, R. Firms and their environments. In: SMELSER, N. J.; SWEDBERG, R. The handbook of economic sociology. Princeton: Princeton University Press, 1994. $848 \mathrm{p}$.

OJODE, L. A. A Resource-Based view of strategic alliances: organizational capabilities, governance, and performance. 2000. Thesis (Doctor of Philosophy in Business Administration) - University of Illinois, Urbana-Champaign.

PÉREZ, M. P.; SÁNCHEZ, A. M. Supplier relations and flexibility in the Spanish automotive industry. Supply Chain Management: An International Journal. v. 6, n. 1, 2001. p 29-38.

PFEFFER, J. A.; SALANCIK, G. The external control of organizations: a resource dependence perspective. New York: Harper \& Row, 1982. 336 p.

PFEFFER, J. A. Size and composition of corporate boards of directors: the organization and its environment. Administrative Science Quarterly. v. 17, n. 2, p. 218-229, 1972.

PIRES, S. R. I. Managerial implications of the modular consortium in a Brazilian automotive plant. International Journal of Operations \& Production Management. v. 18, n. 3, 1998.

Gestão da cadeia de suprimentos (Supply Chain Management) - conceitos, estratégias e casos. São Paulo: Atlas, 2004. 310p.

SACOMANO NETO, M. Redes: difusão do conhecimento e controle - um estudo de caso na indústria brasileira de caminhões. 2004. 259 f. Tese (Doutorado em Engenharia de Produção) - Universidade Federal de São Carlos, São Carlos, 2004.

SALERNO, M. S. et al. Mapeamento da nova configuração da cadeia automotiva brasileira. Disponível em: <http://www.poli.usp.br/pro/cadeia-automotiva2002> Acesso em: 10 out. 2003.

SCRAMIM, F. C. L. Metodologia de apoio a decisão em cadeias de suprimento agroindustriais: um estudo de caso no setor lácteo brasileiro. 181 f. 2003. Tese (Doutorado em Engenharia de Produção) - Universidade Federal de São Carlos. São Carlos, 2003.

SLACK, N.; CHAMBERS, S.; JOHNSTON, R. Administração da produção. 2. ed. São Paulo: Atlas, 2002. $747 \mathrm{p}$.

SWAMINATHAN, A; HOETKER, G.P.; MITCHELL, W. (In) significant others: the impact of buyer-supplier relationships on the survival of modular and architectural component suppliers. Trabalho não publicado. 2002.

SVENSSON, G. Perceived trust towards suppliers and customers in supply chains of the Swedish automotive industry. International Journal of Physical Distribution \& 
Logistics Management. v. 31, n. 9, p. 647-662, 2001.

TAN, K. C. Supply chain management: practices, concerns, and performance issues. The_Journal of Supply Chain Management. Winter, 2002. p. 42- 53.

TOWILL, D. R.; CHILDERHOUSE, P.; DISNEY, S. M. Integrating the automotive supply chain: where are we now? International Journal of Physical Distribution \& Logistics Management. v. 32, n. 2, 2002. p 79-95.

TRIENEKENS, J. Management of Processes in chains: a research framework. 1999. $173 \mathrm{f}$. Thesis Wageningen University, Holland.

WASSERMAN, S.; FAUST, K. Social network analysis. Cambridge: Cambridge University Press, 1994. 857 p.

WILD, R. Production and operations management. 5. ed.
Inglaterra: Cassel Educational Ltd, 1995. 928 p.

WILLIAMSON, O. E. The economic institutions of capitalism - firms, markets, relational contracting. New York: The Free Press- a division of Mc Millan, 1985. 468 p.

Strategizing, Economizing, and Economic Organization. In: RUMELT, R. P.; SCHENDEL, D. E.; TEECE, D.J. Fundamental Issues in Strategy - a research agenda. Harvard Business School Press: 1994. p.361-401.

Mechanisms of governance. New York: Oxford University Press, 1996. 448 p.

ZIRPOLI, F.; CAPUTO, M. The nature of buyer-supplier relationships in co-design activities. International Journal of Operations \& Production Management. v. 22, n. 12, p. 1389-1410, 2002.

\title{
MAIN ASSUMPTIONS OF SUPPLY CHAIN MANAGEMENT: EVIDENCE FROM STUDIES OF THE AUTOMOTIVE INDUSTRY
}

\begin{abstract}
The development of approaches for research on supply chains is fairly recent, since they only began to be studied systematically in the late 1980's. This paper begins with an overview of the main assumptions of the Supply Chain Management (SCM) approach. Based on a partial review of the empirical literature on the automotive industry, the paper then examines whether these assumptions can be confirmed in practice. Since the reviewed literature does not indicate that the aforementioned SCM assumptions have been concretized in the automotive industry, we propose that an initial methodological step be developed to help researchers identify the structural and relational characteristics of the supply chain in question. To contribute to the development of this initial methodological step, a brief summary is made of three schools of thought that may provide the basis for analyzing the structural and relational characteristics of the supply chain: Network Theory, Resource Dependence Theory and Transaction Cost Economics. This analysis of structural and relational characteristics helps evaluate the context in which SCM principles and techniques can be proposed and implemented and, thus evaluate the results that may be achieved through the implementation of SCM.
\end{abstract}

Keywords: supply chain management, supply chain management assumptions, automotive industry. 